\title{
Kateter Yöntemi ile Aort Kapağı Yerleştirilen Bir Olguda Pender'in Sağlığı Geliştirme Modeli'nin Kullanımı
}

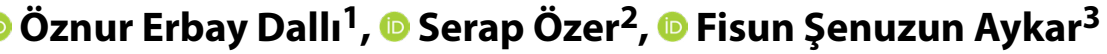

${ }^{1}$ Bursa Uludağ Üniversitesi Tıp Fakültesi, Anesteziyoloji ve Reanimasyon Anabilim Dalı, Bursa

${ }^{2}$ Ege Üniversitesi Hemşirelik Fakültesi, İç Hastalıkları Hemşireliği Anabilim Dalı, İzmir

${ }^{3}$ İzmir Tınaztepe Üniversitesi Sağlık Bilimleri Fakültesi, Hemşirelik Bölümü, İzmir

\begin{abstract}
Özet
Ciddi aort stenozu bulunan ve açık kalp ameliyatı açısından risk taşıyan hastalar için önerilen Transkateter aort kapak implantasyonu (TAVi); yaşam kalitesinde yükselme ve sağ kalımda artış sağlayan bir tedavi yöntemidir. Bu yöntem uygulandıktan sonra multidisipliner bir ekip anlayışının benimsenmesi, hastanın dikkatli ve bütüncül izlemi, yaşam şekli değişikliklerine uyum ve tedavinin başarısı açısından oldukça önemlidir. Multidisipliner ekip içinde hastalara birebir bakım veren hemşireler önemli bir yere sahiptir. Son yıllarda hemşirelik bakımı, bakımın sistematik ve etkili olmasına yardımcı olan kuram ve modeller çerçevesinde oluşturulmaktadır. Bu kuram ve modellerden biri de Pender'in Sağlığı Geliştirme Modeli'dir. Model ile hemşireler bireylerde sağlıklı bir yaşam şekli oluşturmak için davranışsal değişiklik yapmayı hedeflemektedir.

Bu makalede ileri derecede aort stenozu ve dispnesi mevcut olan altmış beş yaşındaki bir erkek hastanın Sağlığı Geliştirme Modeli'ne göre bakım yönetimi süreci ele alınmış ve modelin kullanımına yönelik bir örnek oluşturması amaçlanmıştır.
\end{abstract}

Anahtar sözcükler: Hemşirelik; kuram; Transkateter aort kapağının değiştirilmesi.

The Use of Pender's Health Promotion Model in A Case with Transcatheter Aortic Valve Implantation

\footnotetext{
Abstract

Transcatheter aortic valve implantation (TAVI), which is recommended for patients with severe aortic stenosis and risk for open heart surgery, is a treatment method that provides an increase in quality of life and survival. Adopting multidisciplinary team concept after this procedure is important for patient's careful and holistic approach, adaptation to life changes and the success of treatment. Nurses who provide one-to-one care to patients have important place in multidisciplinary team. In recent years, nursing care has been established within the framework of theories and models that help systematic and effective care. One of these theories is Pender's Health Promotion Model. Nurses can aim to make behavioral changes to create a healthy lifestyle for individuals with this model.

In this article, the care management process of a 65 -year-old male patient with advanced aortic stenosis and dyspnea is discussed according to model and aimed to set an example for the use.

Keywords: Nursing; theory; transcatheter aortic valve replacement.

Cite this article as: Erbay Dallı Ö, Özer S, Şenuzun Aykar F. The Use of Pender's Health Promotion Model in A Case with Transcatheter Aortic Valve Implantation. Turk J Cardiovasc Nurs 2020;11(26):149-154.
}

İletişim (Correspondence): Öznur Erbay Dallı. Bursa Uludağ Üniversitesi Tıp Fakültesi, Anesteziyoloji ve Reanimasyon Anabilim Dalı, Bursa Telefon (Phone): +90 5068692140 E-Posta (E-mail): oznurerbay@gmail.com

Başvuru Tarihi (Submitted Date): 20.08.2020 Kabul Tarihi (Accepted Date): 14.12.2020

oCopyright 2020 by Turkish Society of Cardiology - Available online at www.anatoljcardiol.com

OPEN ACCESS This work is licensed under a Creative Commons Attribution-NonCommercial 4.0 International License. 
$\mathrm{T}$ ranskateter aort kapak implantasyonu açık kalp ameliyatı yapılmadan, kateter yöntemi kullanılarak kalbe biyoprotez aort kapağı takılması işlemidir. ${ }^{[1]}$ Yöntem açık kalp ameliyatı olmadan yapılmasının yanı sıra; işlem süresinin kısa olması, yoğun bakım ve hastanede kalış süresini kısaltması ve konforu arttırması nedeniyle her geçen gün yaygınlaşmaktadır. ${ }^{[1,2]}$ Buna rağmen TAVi sonrası oluşabilecek birçok komplikasyon bulunmaktadır. Bunlar; kanama, miyokard infarktüsü (MI), kardiyak tamponad, inme, enfeksiyon, akut böbrek hasarı $(A B H)$, şok ve ölüme kadar gidebilecek komplikasyonlardır. ${ }^{[3,4]}$ Yapılan bir çalışmada; TAVi uygulanan 42 hastadan 5 'inin (\%11.9) ex olduğu (30 günlük mortalite), hastaların 14'ünde (\%33.3) $\mathrm{ABH}$ geliştiği ve 2 kişiye (\%4.8) hemodiyaliz uygulandığı belirtilmiştir. ${ }^{[5]}$

Kateter yöntemi ile aort kapağı yerleştirilen hastalarda morbidite ve yaşam kalitesini olumlu yönde geliştiren kardiyak rehabilitasyon girişimlerinin yanı sıra uygun sağlık davranışlarının da benimsenmesi (Örn; fiziksel aktivite, kalp koruyucu diyet, kilo kontrolü, sigarayı bırakma, stresten uzak durma, enfeksiyona neden olacak durumlardan kaçınma, verilen ilaç tedavisini sürdürme) uyum ve komplikasyonların önlenmesi açısından gereklidir. ${ }^{[6-9]}$

Günümüzde pek çok araştırmacı hem araştırma problemlerini belirlemek hem de planlanan bir araştırmanın kuramsal çerçevesini geliştirmek için hemşirelik kuram ve modellerinden yararlanmaktadır. ${ }^{[10,11]}$ Hemşirelik kuramına temellendirilerek tasarlanan araştırmalar, hemşirelik bilimsel bilgi içeriğine ve hemşirelik uygulamalarına katkı sağlamaktadır. ${ }^{[12,13]}$

Dünya genelinde hemşirelerin sağlığı koruma ve geliştirmedeki rolü giderek daha sık vurgulanmaktadır. Sağlık hizmetleri harcamalarının artmasıyla, sağlığın geliştirilmesi yalnızca sağlık profesyonellerinden değil halktan da giderek artan bir ilgi görmeye başlamıştır. ${ }^{[14]}$ Sağlığı Geliştirme Modeli (SGM) Nola J. Pender tarafından 1987 yılında geliştirilmiş ve 1996 yılında revize edilmiştir. Model, sağlığı geliştirme alanındaki uygulamalara yol gösterecek nitelikte olup sağlığı koruma modellerinin tamamlayıcısı olmayı hedeflemektedir. ${ }^{[15]}$ Modelin amacl; yaşam şekline ilişkin sağlığı geliştirme davranışlarının bileşenlerini açıklamak, bireyin deneyimlerini ve sağlık davranışına ilişkin algılarını etkileyebilecek faktörleri değerlendirmek ve sağlıklı yaşam şekline ilişkin davranışların belirleyicilerinin anlaşılması için sağlık profesyonellerine yardımcı olmaktır. ${ }^{[16,17]}$

Sağlığı Geliştirme Modeli, hemşirelik uygulamalarının birçok alanında kullanılabilmektedir. Yeni bir kronik hastalık tanısı konmuş bireylerde (Örn; diyabet, hipertansiyon) has- talığa uyum sağlanmasında ya da geçirilen bir operasyondan (Örn; TAVi, bypass) ve sağlık probleminden (Örn; MI) sonra değişebilecek günlük yaşam şekline yönelik olarak sağlıklı yaşam davranışlarının geliştirilmesinde bu teoriden yararlanılabilmektedir. ${ }^{[16-18]}$

Bu makalede TAVI uygulanan bir olgunun SGM kullanılarak sağlık davranışlarının geliştirilmesine yönelik hemşirelik bakımının değerlendirilmesi amaçlanmıştır. Bu olgu için SGM seçilerek modelin temel kavramları çerçevesindeki değerlendirmenin ve bütüncül yaklaşımın gerekliliği vurgulanmıştır.

\section{Pender'in Sağlığı Geliştirme Modeli}

Pender'in "Sağlığı Geliştirme Modeli", bireyin özgeçmişini ve kendisine yönelik algısını değerlendirerek bütüncül bir yaklaşım sunmaktadır. Model, hastalıktan veya durumdan kaçınmayı bir sağlık davranışı motivasyonu olarak ele almakta, sağlığı geliştirme davranışını ön görmeyi vurgulamakta ve bireyin sağlığını kendisinin kontrol etmesine fırsat vermektedir. ${ }^{[14,18]}$ Model her bir bireyin davranışını ve tercihlerini göz önünde bulundurması nedeniyle yararlıdır.

Model iki temel teori üzerine şekillenmiştir; ${ }^{[15]}$

- Beklenti Değer Teorisi-Bireyler sonuçlarına değer verdikleri amaçları gerçekleştirmek için mümkün olduğunca istekli davranır.

- Sosyal Bilişsel Teori-Düşünceler, davranışlar ve çevre birbirini etkilemektedir. İnsanların düşünceleri davranışlarına yön verir.

Modelin temel kavramları birey, çevre, bakım, sağlık ve hastalıktır. Revize edilen (1987) modelde, Bilişsel Algısal Faktörlerde yer alan bileşenlerden bazılarının isimleri değişmiştir. $[16,17]$ Modifiye Edici Faktörler (demografik özellikler, biyolojik özellikler, kişilerarası etkileşim, duruma özgü faktörler, davranışa özgü faktörler) ve Sağlığı Geliştirici Davranışa Katılma (davranışı uygulamaya karar verme, davranışın başlaması) durumu eklenmiştir. Daha sonra modele 1996 yılında, önceki davranışlarla ilişki, acil taleplerin ve tercihlerin karşılanması ve eylem planının sorumluluğu alanları eklenmiştir (Şekil 1). ${ }^{[15-18]}$

\section{Sağlığı Geliştirme Modeline Göre Bakım Yönetimi Süreci}

\section{Kateter Yöntemi İle Aort Kapağı Yerleştirilen Olgunun Profili}

Onamı alınarak görüşmenin başlatıldığı altmış beş yaşındaki erkek hasta C.D. $1.78 \mathrm{~cm}$ boyunda ve 94 kilodur. Emekli 


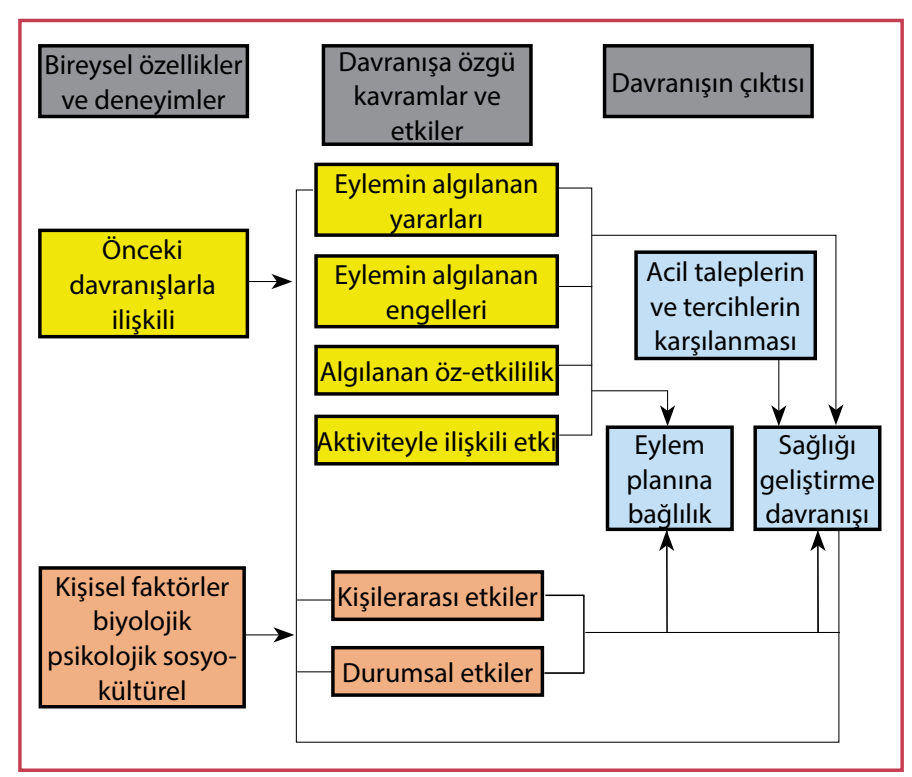

Şekil 1. Sağlığı geliştirme modeli.

olan ve sosyal güvencesi olan C.D. evli ve iki çocuk sahibidir. Çabuk yorulma, eforla başlayan, şiddetli ve sıkıştırıcı olduğu ifade edilen göğüs ağrısı ve dispne şikayetleri ile hastaneye başvuran ve anjiyo uygulanan olguda aort stenozu saptanmış ve kardiyoloji servisine yatışı yapılarak stenozun ve dispnenin ileri derecede olması nedeniyle TAVi işlemi gerçekleştirilmiştir. C.D. işlem sonrası yoğun bakımda izlenmiştir.

Sağlık öyküsünde sigara (günde 2 paket, 2002 yılında bırakmış) ve alkol kullanımı (her gün) olduğunu, ayrıca 2002 yılında Ml, 2010 yılında ise bypass ameliyatı geçirdiğini belirten olgunun aile sağlık öyküsünde babasının MI, annesinin ise akciğer kanseri nedeniyle vefat ettiği bildirilmiştir.

C.D.'nin geçmiş bypass ameliyatı sonrasında nasıl hissettiği, sonucunu değerlendirmesi istenildiğinde bypass sonrasında hiçbir değişim hissetmediğini, yine kötüleştiğini, iyileşmediğini ifade etmiştir. Kateter yöntemi ile aort kapağı yerleştirme hakkında ise işlem öncesi stresli olduğunu, ne yaşayacağını bilmediğini, kapalı bir ameliyat olduğu için aklında belirsizlikler olduğunu ve korktuğunu belirtmiş, işlem sorasında ise çok rahatladığını, yeniden yaşamaya başlamış gibi hissettiğini ifade etmiştir. Olgunun başa çıkma davranışları sorgulandığında; genellikle içe kapanık olduğunu, kimseden yardım istemediğini söylemiştir. Bypass sonrasında kendisini hala kötü hissetmesi nedeniyle yaşam şekli değişikliklerine ilişkin verilen bilgi ve uygulamalara uyum sağlayamadığını ifade eden C.D.'nin, bu nedenle tekrar prognozunun kötüleştiği düşünülmektedir.

C.D.'nin fiziksel değerlendirilmesinde herhangi bir sorun saptanmamıştır. Görüşme yapıldığı sıradaki yaşamsal bulguları; vücut sıcaklığı: $36.3^{\circ} \mathrm{C}$, kan basıncı: $97 / 63 \mathrm{mmHg}$, nabız: 89/dk, solunum: 18/dk, oksijen saturasyonu: $\% 95$ olarak saptanmıştır. Laboratuvar bulgularında; total kolesterol: $288 \mathrm{mg} / \mathrm{dL}$, LDL kolesterol: $211 \mathrm{mg} / \mathrm{dL}$ ile yüksek bulunmuştur. Diğer biyokimya ve hematoloji bulgularında ciddi bir sorun gözlenmemiştir.

\section{Sağlığı Geliştirme Modeli'ne Göre Olgunun Değerlendirilmesi}

C.D.'nin genel sağlık durumuna ilişkin bilgi eksikliği yaşadığı ve başa çıkma davranışlarının bu bilgi eksikliğini etkilediği görülmüştür. Bypass sonrasında kendini hala iyileşmemiş gibi hissettiğini belirten olgunun gerçekleştirilmesi gereken yaşam şekli değişiklerini uygulamadığı, bu konuda bilgi ve eğitime ihtiyacı olduğu saptanmıştır. Uygulanan işlem sonrasında yaşadığı rahatlama ve iyileşme duygusu, daha pozitif hissetmesine ve uyumlu davranışlar sergilemesine yol açmıştır. Bu duruma yönelik C.D.'nin prognozunun yeniden kötüleşmemesi için model ışığında bazı davranış değişiklikleri hakkında bilgi ve eğitim verilmesi planlanmıştır (Şekil 2).

\section{Bireysel Özellikler ve Deneyimler}

Bireyin geçirmiş olduğu başka bir ameliyatına ilişkin önceki deneyimi ve kişisel özellikleridir. Bireyin daha önce kendisinde ya da aile bireylerinde bu girişimi deneyimlemiş olması ayrıca uygulanan kişinin biyolojik olarak yaşı, cinsiyeti, sahip olduğu kardiyak risk faktörleri, fonksiyonel

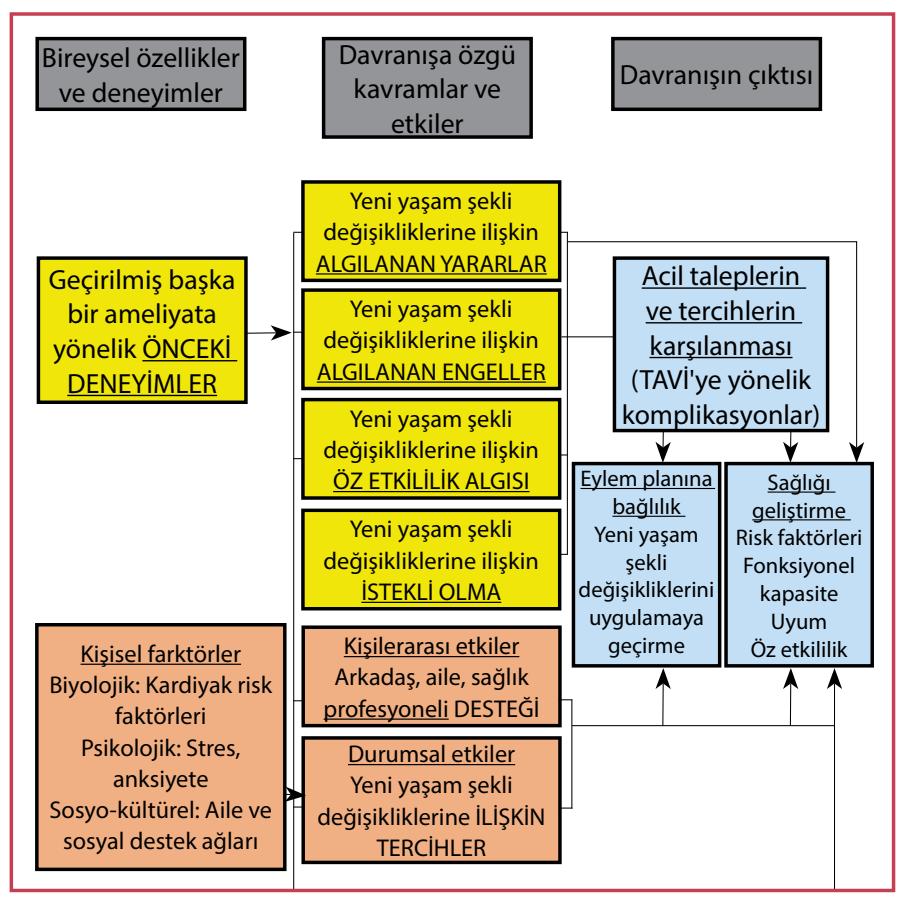

Şekil 2. TAVi uygulanan bireylerde sağlığı geliştirme modelinin kullanılması. 
kapasitesi, psikolojik ve sosyokültürel durumu sağlığı geliştirmedeki davranış değiş̧ikliğini etkileyecek faktörlerdir. ${ }^{[15]}$ C.D.'nin bypass ameliyatı sonrası yaşadığı olumsuz deneyimleri TAVI işlemine yönelik de bir strese neden olmuştur. Ayrıca bu deneyim belirsizlikler yaşamasına, korku ve endişe duymasına yol açmıştır. İşlem sonrası ise geçmişte yaşadığı olumsuzlukların gerçekleşmediğini deneyimleyince korkusu ve endişesi azalmış, kendisini daha iyi hissettiğini ifade etmiştir.

\section{Davranışa Özgü Kavramlar ve Etkiler}

Bu kapsamda aşağıda belirtilen algılar yer almaktadır.

Eylemin Algılanan Yararları: Bir davranışı ya da eylemi olumlu olarak algılamak, o davranışın kazanılmasını hızlandırmaktadır. ${ }^{[15]}$ Olgunun TAVi işlemine yönelik olumlu duyguları, davranış kazanmada etkili olmuştur. C.D.'ye kardiyak beslenme ve uygun egzersizin TAVi sonrası gelişebilecek komplikasyonların önlenmesine yönelik kendi sağlığı açısından olumlu olduğu belirtilmiştir. Hastanın olumlu duyguları, verilen beslenme ve egzersize ilişkin eğitimi daha iyi anlamasına, öz etkililik algısının artmasına ve davranışların yararını anlamasına neden olmuştur.

Eylemin Algılanan Engelleri: Birey yeni bir davranışa başlama ve sürdürme sürecinde kişisel, psikolojik, kültürel kaynaklı pek çok engelle karşılaşabilmektedir. Davranışla ilgili olumsuz duygular, davranışı geliştirmeyi de olumsuz yönde etkilemektedir. ${ }^{[15]}$ Olgu bypass sonrası yaşadığı olumsuz deneyimleri TAVi sonrasında da yaşayacağından korktuğunu belirtmiştir. Bypass sonrası davranış ve yaşam şekli değişiklerini uygulamada sorunlar yaşayan olguda kilo vermenin, uygun egzersiz programının ya da diyetin yararı olmayacağı düşüncesinin olduğu görülmüştür. Olgu kendisini bu düşünceye iten nedenlerin yeni davranış ve yaşam şekline uyum sağlayamama endişesi olduğunu belirtmiştir. C.D.'de bu davranışları geliştirmeye yönelik olumsuz duygular, verilen eğitimle ve bilgi eksikliğinin giderilmesiyle önlenmeye çalışılmıştır. Olgu olumsuz duygularının azaldığını belirterek, yaşam şekli değiş̧ikliklerini yerine getirmede uyum sağlamaya başlamıştır.

Algılanan Öz Etkililik: Öz etkililik bireyin sağlığını geliştirmede veya sağlıkla ilgili sorunlarını çözümlemede etkin olma gücüdür. Düşük öz etkililiğe sahip olan bireyler yeni sağlık davranışlarına ya da alışılmış davranışları değiştirmeye daha az yatkındırlar. ${ }^{[15]}$ Olguya yaşam aktivitelerinin ve davranış değişikliğinin TAVi sonrası oluşabilecek komplikasyonları önlemedeki yararları açıklanmış, kendisinin başarıyı elde etmede merkez noktada olduğu vurgulanmış, yeni durumuna uyum sağlaması kolaylaştırılmıştır. Olgunun aldığı bu eğitim ve danışmanlık sonrası sağlıklı yaşam davranışını başarı ile yerine getirmede kendisine olan güveni artmıştır.

Aktiviteye İlişkin Duygu Durumu: Davranış öncesi, sırası ve sonrasında oluşan duygulardır. Bu duygular, bireyin sağlıklı yaşam davranışını sürdürmesini sağlayan duygulardır. $^{[15]}$ C.D. bypass sonrası taburcu olduğunda davranış değiştirmeye istekli olduğunu ancak daha sonra yaşadığı olumsuzluklar nedeniyle bu isteğinin azaldığını belirtmiştir. Bunun yanı sıra hasta uyguladığı egzersiz programının ve diyetin işe yaramadığı duygusuna kapılmıştır. Bu durum göz önüne alındığında hastane hemşirelik yönetimi ile işbirliği yapılarak C.D.'nin taburcu olduktan sonra da poliklinik ziyaretlerinde tekrar TAVi hakkında eğitim ve danışmanlık alması, olumlu duygular geliştirmesi ve sürdürmesi için destek olunmuştur.

Kişilerarası Etkiler: Çevredeki bireylerin kişiye, davranışa ilişkin verdiği destektir. ${ }^{[15]}$ Kapak yerleştirme işlemi sonrası yaşam şekli değişikliklerine kolayca uyum sağlamada aile ve yakınların desteği önemlidir. C.D., özellikle eşinin daha çok destek sağladığını, çocuklarının şehir dışında olması nedeniyle çok ziyaret edemediklerini belirtmiştir. Verilen eğitime eşi de dahil edilmiş, böylece bilgi eksikliği giderilerek C.D.'ye nasıl destek olacağı konusunda yardımCl olunmuştur. Örneğin evde yemekleri hazırlayan eşinin, TAVi sonrası diyet önerilerine uygun olarak yemek yapma alışkanlığını düzenlemesi ve önerilen egzersiz programında C.D.'ye eşlik etmesi hakkında bilgiler verilmiştir. Hastane diyetisyenliği ile işbirliği yapılarak tuzsuz ve yağsız bir kardiyak diyet oluşturulması sağlanmış, C.D. ve eşine verilmiştir.

Durumsal Etkiler: Bireysel algılar, ortamdaki herhangi bir durum veya ortamın şartları davranışı kolaylaştırmakta ya da engel olmaktadır. Durumsal etkiler doğrudan ya da dolaylı olarak sağlık davranışını etkileyebilmektedir. ${ }^{[15]}$ isşlem sonrası kardiyak diyet, egzersiz, kullanıyor ise sigarayı ve alkolü bırakma, stresten uzak durma gibi değişikliklerin bu tarz yaşantıdan uzak olan C.D. için kolay olmayacağı ancak sağlıklı davranışlar benimsemesinin gelecekteki yaşamını olumlu etkileyeceği ve yaşam süresini uzatmaya yardımcı olacağı konusunda bilgi verilmiştir. Bazı alışkanlıkların değiştirilmesinin sağlıklı bir yaşam sürülmesine katkıda bulunacağı vurgulanmıştır. C.D.'nin konu hakkında farkındalığı artırılarak davranış değiştirmesi kolaylaştırılmıştır.

\section{Davranış Çıktısı}

Davranışa İlişkin Plan Yapma: Davranış hakkında plan yapma, davranışla ilgili niyet kavramını içermektedir. Bu plana bağlılık, önemli bir tercih ortaya çıkmadıkça bireyde yeni davranış oluşumuna neden olmaktadır. ${ }^{[15]}$ C.D.'nin TAVi sonrasında oluşabilecek risklere yönelik yaşına ve bo- 
yuna uygun bir kiloda olmasının önemi hakkında diyetisyenle birlikte bilgi verilmiş ve uygun bir kilo sınırına ulaşmak için diyet ve egzersiz planlaması yapılmıştır. C.D.'nin bu planı uygulamada istekli olduğu görülmüştür.

Acil, Birbiriyle Yarışan İstekler ve Tercihler: Alternatif davranışlar içinde bireylerin kendi tercihlerini kullanmasıdır. Aktiviteye karar vermeden önce var olan planlı davranış için bu alternatifler görüşülerek "yarar ve engel" kavramları belirlenmektedir. Bireyin kontrolü elden bırakmaması gerekmektedir. ${ }^{[15]}$ Burada C.D.'ye TAVi sonrasında kilosunu kontrol etmek için yemek miktarını az seçmesinin yararlı olduğu ancak sadece bu durumun düşük kontrole sahip olduğu açıklanmıştır. Buna karşın yemek alışkanlığını kalp koruyucu tercihlerden yana kullanması gerektiği, böylece önceliklerini daha iyi belirleyebileceği ve davranışları üzerinde daha yüksek kontrol sağlayabileceği belirtilmiştir.

Sağlığı Geliştirme Davranışı: Bireyin istendik davranışları göstermesi ve bu davranışların yaşam şekli biçimi haline getirilmesidir. İstendik davranışın gösterilmesi ile sağlık/ iyilik hali yükseltilmiş, işlevsel yetenek geliştirilmiş ve daha iyi bir yaşam kalitesi sağlanmış olur. ${ }^{[15]}$ Bu faktör göz önüne alındığında TAVi sonrası taburculuk için verilen eğitimin davranış ve yaşam şekli değişiklerine olan etkisini değerlendirmek adına C.D.'nin poliklinik kontrol günlerinde yapılan laboratuvar tetkiklerinde kolesterol düzeyinin azalması, kilo vermesi, kardiyak diyetini ve ilaç tedavisini eksiksiz sürdürmesi gibi sonuçlara ulaşılması beklenmektedir. Tedavisinin tamamlanması ile C.D.'nin taburculuğu gerçekleştirilmiş ve kontrol amacıyla polikliniğe ziyareti planlanmıştır. C.D.'nin poliklinik ziyaretinde kilosunun 89'a düştüğü görülmüş, görüşmede her gün 30 dakikalık yürüyüşler yaptığını ve diyetini aksatmadığını ifade etmiş̧tir. Laboratuvar bulgularında Total Kolesterol: 241 mg/dL, LDL Kolesterol: 186 mg/ dL ile gerileme olduğu görülmüştür. C.D.'nin TAVi sonrası yaşadığı olumlu duyguların yeni yaşam şekline uyum sağlamasında etkili olduğu görülmüştür. Ayrıca tekrar eğitim ve danışmanlık verilerek sağlıklı davranışlarını sürdürmenin önemi bir kez daha vurgulanmıştır.

\section{Tartışma}

Kardiyak rehabilitasyon ve yaşam şekli modifikasyonu, TAVi de dahil olmak üzere birçok kardiyak girişim sonrası ve hastalık sürecinde bireyin yaşamını sağlıklı bir şekilde devam ettirmede önem taşımaktadır. ${ }^{[19]}$ Kateter yerleştirilen hastalar, cerrahi kapak replasmanı uygulanan hastalara göre daha fazla komorbiditeli ve kırılgan bir profile sahiptir. Bu nedenle TAVi sonrası orta ve uzun vadeli, sonuçları iyileştirmeyi amaçlayan stratejilerin ve kardiyak rehabilitasyon programlarının benimsenmesi şarttı. ${ }^{[20]}$ TAVi uygulanmış aort darlığı olan bireylerin fonksiyonel kapasite ve yaşam kalitesini arttırmada kardiyak rehabilitasyon programının etkinliğinin araştırıldığı bir meta-analiz çalışmasında, kardiyak rehabilitasyon programının 6-Dakika Yürüme Testi ve Barthel Günlük Yaşam Aktiviteleri İndeksi değerlendirilmelerinde anlamlı iyileşmeler sağladığı belirlenmiştir. ${ }^{[21]}$ Başka bir çalışmada TAVi sonrası hastalarda $(n=136)$ çok bileşenli bir kardiyak rehabilitasyon programının etkileri araştırılmış, hastalarda SF-12 Yaşam Kalitesi Ölçeği puanlarında ve 6-Dakika Yürüme Testi sonuçlarında anlamlı artışlar saptanmıştır. ${ }^{[22]}$ Sonuç olarak baktığımızda, TAVi hastaları için kardiyak rehabilitasyon programlarının etkin olduğunu söyleyebiliriz. Olgumuzda gelişen olumlu değişim ve artan uyum düzeyi göz önüne alındığında TAVi uygulanan hastalarda kardiyak sağlık davranışlarını geliştirme, bilişsel ve davranışsal değişim sağlama, kardiyak rehabilitasyon programlarına uyumu arttırmada Pender'in modeli tercih edilebilir. Model; Ml, diyabet, kanser gibi birçok hastalığın yönetimine yönelik bireyin öz yeterliliğinin artırılmasında ve yaşam şekli değişikliği oluşturmada etkili olarak bulunmuştur. ${ }^{[16-18]}$

Kateter yöntemi ile aort kapağı yerleştirilmesi işıleminin başarısı sadece işlemin komplikasyonsuz gerçekleştirilmesi değil, ayrıca hemşireler tarafından hastanın dikkatli ve bütüncül bir yaklaşımla izlem sağlanmasına; fiziksel aktivite, diyet ve ilaç tedavisinin yönetimi hakkındaki taburculuk eğitimine de odaklanmaktadır. ${ }^{[3,4,6,7]}$ Yapılan bir olgu çalışmasında, TAVi işlemi sonrası kanama ve kalp iletim komplikasyonu yaşayan bir bireyin hemşirelik izlem sürecinin önemi ortaya konmuştur. ${ }^{[2]}$ Bu olguda gelişen komplikasyonlar erken fark edilerek uygun tedavi ve hemşirelik girişimleri ile kontrol altına alınmış, hasta sağlıklı bir şekilde evine taburcu edilmiştir. ${ }^{[2]}$ Bu olgu sunumumuzda da Pender'in modeli ile hastaların izleminin sağlıklı ve uyumlu şekilde gerçekleştirilebileceği ve komplikasyonların gelişmesinin önlenebileceği gösterilmiştir.

\section{Sonuç}

Pender'in Sağlığı Geliştirme Modeli'ne uygun geliştirilen bir rehber eşliğinde TAVI uygulanan hastalara verilen eğitimin olumlu etkileri, bu olgu çalışmasında gözlenen pozitif değişim, memnuniyet ve uyum artışı ile kanıtlanmıştır. Kardiyoloji hemşireleri, TAVi uygulanan olgularda bu modeli etkin kullanarak hastalara, yaşam şekli değişikliklerini benimsemesi ve kardiyak rehabilitasyona uyum sağlaması açısından destek olabilir.

Hakem Değerlendirmesi: Dış bağımsız. 
Çıkar Çatışması: Yazarlar arasında herhangi bir çıkar çatışması bulunmamaktadır.

Bilgilendirilmiş Onam: Olgu sunumunun yayınlanması için yazılı bilgilendirilmiş onam alındı.

Yazarlık Katkıları: Konsept: Ö.E.D.; Dizayn: Ö.E.D.; Veri Toplama veya İşleme: Ö.E.D.; Analiz veya Yorumlama: Ö.E.D., S.Ö., F.Ş.A.; Literatür Arama: Ö.E.D.; Yazan: Ö.E.D., S.Ö., F.Ş.A.

\section{Kaynaklar}

1. Yücel G, Paker T, Akçevin A, Sezer A, Eryilmaz A, Ozyiğit T, et al. Transcatheter aortic valve implantation: the first applications and early results in Turkey. Turk Kardiyol Dern Ars 2010;38(4):258-63.

2. Türen S, Atakoğlu R. Transkateter Aort Kapak İmplantasyonu (TAVI) Uygulanan Hastalarda Hemşirelik Bakımı: Olgu Sunumu. Turk J Card Nur 2016;7(13):127-35. [CrossRef]

3. Erpicum MC, Radermecker MA, Defraigne JO, Legrand V. Nursing care after Transcatheter Aortic Valve Implantation with the Medtronic CoreValve Revalving ${ }^{\circledR}$ system. Eur J Cardiovasc Nurs March 2011;10:35. [CrossRef]

4. Türen S, Enç N. Transkatater Aort Kapak İmplantasyonu (TAVI) ve Hemşirelik Bakımı. Turk J Card Nur. 2014;5(7):1-11. [CrossRef]

5. Türen S, Yıldırım A, Satılmışoğlu MH, Öz K. Incidence, risk factors and prognostic impact of acute kidney injury on 30-day mortality after transcatheter aortic valve implantation. Turkish Journal of Thoracic and Cardiovascular Surgery 2017;25(4):573-9. [CrossRef]

6. Kiel MK. Cardiac rehabilitation after heart valve surgery. PM R 2011;3(10):962-7. [CrossRef]

7. Horstkotte $D$, Lengyel $M$, Mistiaen WP, Völler $H$, Reibis $R$, Bogunovic N, et al; Society of Heart Valve Disease. Recommendations for post-discharge patient follow up after cardiac valve interventions: a position paper. J Heart Valve Dis 2007;16(6):575-89.

8. Butchart EG, Gohlke-Bärwolf C, Antunes MJ, Tornos P, De Caterina $\mathrm{R}$, Cormier B, et al; Working Groups on Valvular Heart Disease, Thrombosis, and Cardiac Rehabilitation and Exercise Physiology, European Society of Cardiology. Recommendations for the management of patients after heart valve surgery. Eur Heart J 2005;26(22):2463-71. [CrossRef]

9. Haight K. Caring for patients after transcatheter aortic valve replacement. American Nurse Today 2017;12(8):10-6.
10. Rogers C, Keller C. Roy's adaptation model to promote physical activity among sedentary older adults. Geriatr Nurs 2009;30(2 Suppl):21-6. [CrossRef]

11. Heller BR, Oros MT, Durney-Crowley J. The future of nursing education. Ten trends to watch. Nurs Health Care Perspect 2000;21(1):9-13.

12. Koç Z, Keskin Kızıltepe S, Çınarlı T, Şener A. The use of theory in nursing practice, research, management and education. HEAD 2017;14(1):62-72. [CrossRef]

13. Bond $A E$, Eshah NF, Bani-Khaled M, Hamad AO, Habashneh $\mathrm{S}$, Kataua' $\mathrm{H}$, et al. Who uses nursing theory? A univariate descriptive analysis of five years' research articles. Scand J Caring Sci 2011;25(2):404-9. [CrossRef]

14. Bahar Z, Açıl D. Sağlığı Geliştirme Modeli: Kavramsal Yapı. DEUHYO ED 2014;7(1):59-67.

15. Murdaugh CL, Parsons MA, Pender NJ. Individual Models to Promote Health Behavior. In: Dodge A, (editor). Health Promotion in Nursing Practice. 8th eds. NY: Pearson Education; 2018.

16. Ersin F, Bahar Z. Sağlığı Geliştirme Modelleri'nin Meme Kanseri Erken Tanı Davranışlarına Etkisi: Bir Literatür Derlemesi. DEUHYO ED 2012;5(1):28-38.

17. Çalık A, Kapucu S. Diyabetli Hastalarda Sağlıklı Yaşam Biçimi Davranışlarını Geliştirme: Pender'in Sağlığı Geliştirme Modeli. Hacettepe Üniversitesi Hemşirelik Fakültesi Dergisi 2017;4(2):62-75.

18. Sevinç S. Miyokart İnfarktüsü Geçirmiş Bireylerde Yaşam Şekli Değişikliği: Pender'in Sağlığı Geliştirme Modeli. Turk J Card Nur 2016;7(14):147-52. [CrossRef]

19. Mampuya WM. Cardiac rehabilitation past, present and future: an overview. Cardiovasc Diagn Ther 2012;2(1):38-49.

20. Butter C, Groß J, Haase-Fielitz A, Sims H, Deutsch C, Bramlage $P$, et al. Impact of Rehabilitation on Outcomes after TAVI: A Preliminary Study. J Clin Med 2018;7(10):326. [CrossRef]

21. Ribeiro GS, Melo RD, Deresz LF, Dal Lago P, Pontes MR, Karsten M. Cardiac rehabilitation programme after transcatheter aortic valve implantation versus surgical aortic valve replacement: Systematic review and meta-analysis. Eur J Prev Cardiol 2017;24(7):688-97. [CrossRef]

22. Eichler S, Salzwedel A, Reibis R, Nothroff J, Harnath A, Schikora $M$, et al. Multicomponent cardiac rehabilitation in patients after transcatheter aortic valve implantation: Predictors of functional and psychocognitive recovery. Eur J Prev Cardiol 2017;24(3):257-64. [CrossRef] 